\title{
Exploring the Classification and Restructuring of Chemical Industrial Cities in China: The Perspectives of Sectoral and Spatial Differences
}

\author{
Hui Zou $\mathbb{D}^{1},{ }^{1,2}$ Xuejun Duan $\mathbb{D}^{\mathbb{D}},{ }^{1,2,3}$ Lei Wang $\mathbb{D}^{1,2,4}$ and Tingting Jin $\mathbb{D}^{1,3}$ \\ ${ }^{1}$ Nanjing Institute of Geography and Limnology, Chinese Academy of Sciences, Nanjing, China \\ ${ }^{2}$ Key Laboratory of Watershed Geographic Sciences, Nanjing Institute of Geography and Limnology, Chinese Academy of Sciences, \\ Nanjing, China \\ ${ }^{3}$ University of Chinese Academy of Sciences, Beijing, China \\ ${ }^{4}$ Department of Planning and Environmental Management, School of Environment, Education and Development, \\ The University of Manchester, Manchester, UK
}

Correspondence should be addressed to Xuejun Duan; xjduan@niglas.ac.cn and Lei Wang; wanglei@niglas.ac.cn

Received 26 August 2020; Revised 27 November 2020; Accepted 28 February 2021; Published 12 March 2021

Academic Editor: Jun Yang

Copyright (c) 2021 Hui Zou et al. This is an open access article distributed under the Creative Commons Attribution License, which permits unrestricted use, distribution, and reproduction in any medium, provided the original work is properly cited.

As an economic pillar, major resource consumer, and polluter of cities, the chemical industry determines many cities' transformation, prosperity, and decay. It is thus a major concern for achieving the UN Sustainable Development Goals. In China, which is at the stage of accelerated industrialization that is varied across regions, the chemical industry has gradually retreated from developed cities, such as Beijing and Shanghai, in the eastern region, and has become the inevitable choice for industrialization of less-developed cities, such as Xi'an, Chengdu, and Chongqing, in the western region. This study took the perspectives of chemical industrial sectors and their spatial differences to understand the changing patterns of the chemical industry and its dominant cities. It identified chemical industrial cities (CICs), examined their spatial-temporal patterns with respect to their industry scale and structure, and accounted for factors influencing the spatial evolution from coastal areas to inland regions. The results show that large CICs were mainly located in coastal port regions with balanced industrial sectors, while small CICs were mainly distributed in inland areas with abundant oil and coal resources and a single dominant industrial sector. The location factors of ports, markets, and technology play important roles in the eastern region, while resource conditions and foreign direct investment promote the chemical industry's development in the central, western, and northeastern cities. These findings improve the understanding of CICs' spatial transformation and shed light on the policy-making of chemical industrial development in China and other developing countries.

\section{Introduction}

The chemical industry has become one of the strongest and largest industries in the world $[1,2]$. Its development has triggered economic growth and the rise of cities as well as of countries. The chemical, and other related, industries must consider environmental protection, pollution emissions, human health, and circular economy, among others, all of which have a high correlation to the United Nations' Sustainable Development Goals [3]. Many of the world's most important urban agglomerations and economic belts-such as areas along the Rhine, Gulf of Mexico, Tokyo Bay, and Yangtze River Delta-have (or used to have) a high concentration of chemical industries. The close relationship between the chemical industry and a city (and its population) reflects the global consumption and market orientation of chemical production $[4,5]$. The economy of cities that rely on chemical and related industries can develop rapidly [6-8]. However, the decline in oil production and global oil prices has led cities with chemical industries to 
diversify their industrial and service activities [6]. These industries have different industrial sectors and varied reasons for driving the industrial chain $[9,10]$. Because of the varied industrial sectoral structures, there are different divisions of labor and cooperation models in the development of the urban chemical industry $[11,12]$, which have led to different product characteristics and industrial chains [13]. Therefore, research on important chemical industrial cities (CICs), based on the layout of their chemical sectors, has become a bridge connecting industrial economics, urban geography, and regional sustainable development.

China's chemical industry has been the largest globally in terms of revenue since 2011, contributing to half the growth of the global chemical market over the past two decades [14]. Since joining the World Trade Organization, China's chemical industry has become an important support for the country's urban economic development; it has not only ensured rapid growth of the regional economy but also created increasingly prominent ecological and environmental contradictions and security risks [4, 15-17]. Chemical hazards have become an important global issue; for example, 169 chemical accidents have been recorded in France from 1974 to 2014 [18]. Chemical accidents are particularly prominent in China, such as the " 3.21 " chemical explosion in Xiangshui County, Jiangsu Province, which caused 78 deaths and 1.986 billion yuan in economic losses [14].

Overreliance on the chemical industry also exacerbates the "resource curse" phenomenon [19], which has caused many cities to face difficulties in their economic transitions as well as economic recessions due to excessive dependence on resources [20]. Therefore, many economically developed cities have begun to switch out of the chemical industry and develop non-/low-polluting industries, which scholars call the post-oil industry era $[6,21,22]$. Many resource-based cities and CICs, such as Pittsburgh (USA), Kitakyushu (Japan), Ruhr (German), and Lorraine (France), have already successfully achieved sustainable development under different policies [20]. However, as China is still at the stage of rapid industrialization, the chemical industry continues to be an important pillar industry in most cities. For example, although Beijing, Shanghai, and Guangzhou are economically developed, they still have a large number of chemical industries [23]. Nevertheless, it is worth noting that these developed cities have begun to transition out of the chemical industry (especially highly polluting sectors, such as coking). This has caused dramatic change and restructuring in the various CICs in China, especially from the perspectives of sectoral and regional geographic differences. Studying this change can help us discover this developing country's characteristics as well as related policies that can be created.

This study uses enterprise-level data to explore the evolution of the chemical industries' spatial layout in Chinese cites, identify the CICs and the reconstruction of the industrial scale and sector, and discuss the CICs' influencing factors and locations. Based on these contexts, this study aims to answer three related questions:

(i) In which CICs were China's chemical industries mainly distributed, which CICs were rising, which were declining, and how did their market size change over the last 20 years of rapid industrialization?

(ii) How were the CICs differentiated geographically? Did the transformation of the chemical industrial structures cause the rise and fall of the CICs? These questions are developed based on China's geographical and economic differentiation, as the country is obviously divided into the eastern coastal, central, western, and northeastern regions where the chemical industrial sectors, including oil refining, coking, and those producing fertilizers, and pesticides, are quite different.

(iii) What causes the CICs' spatial pattern evolution in China with respect to industrial output scale and industrial sectors across different regions?

\section{Literature Review}

2.1. Chemical Industrial Layout, Industrial Chains, and Clusters. With the development of refining and chemical integration, the agglomeration factor has attracted extensive attention from scholars, resulting in increased research on agglomeration and clustering of the chemical industry. The case of European oil refining companies shows that agglomeration is an important factor affecting the distribution of companies, and the distribution of the upstream, midstream, and downstream industries has obvious differences [24]. A German case study reveals that the chemical industry's spatial layout shows a significant weak geographical proximity effect, and its spatial agglomeration pattern exceeds the traditional industrial cluster $[25,26]$.

Research on the spatial layout of China's national-scale chemical industry originated in the 1990s, and it found that in the beginning, China's chemical industry moved to the coastal areas from its earlier location near raw materials $[23,27]$. Thus, China's high coal-consuming industries are mainly concentrated in the eastern coastal and northern regions, and they gradually shifted from the south to the north [19]. The chemical industry accelerated the globalization trend and increased the complexity of the supply chain, but the development of its industry chain is complicated, as cities are increasingly relying on direct division of labor and collaboration in the perfect chemical industry chain [28]. Moreover, integrated supply chain modeling of the chemical industry is crucial for enterprises to become competitive, as this model considers the dimensions of geography, decision-making level, business field, and so on [29]. For the petrochemical downstream industry, at the strategic and global planning level of the manufacturing 
plant network, raw material procurement and distribution, production capacity utilization, transportation mode utilization, and demand allocation are important research areas $[9,30]$.

2.2. Development and Restructuring of CICs. Existing research has focused on the development and layout of industrial cities, including the industrial layout and environmental effects of mining, coal, coal chemical, and resource-based cities [6,20,31-33]. With the evolution of the unreasonable industrial structure of coal-dependent cities, which are mainly distributed in China, Australia, the United States, Russia, and India, the corresponding cities are facing resource wastage, pollutant emissions, and fragile ecological structures [34]. Furthermore, China's resourcebased cities are divided into cities dependent on oil, coal, metal, nonmetals, and forest resources [20]. A case study in Huai'an, China, found that a salt chemical city has evolved from an industrial complex with high energy consumption into a consolidated growth-promoting city-scale diversification system, which illustrates the interaction between the chemical industry and city development [35]. Many traditional petrochemical cities also aim to end their dependence on petrochemicals, such as cities in the Arabian Peninsula and the Gulf region [21]. Affected by the macro-control of national policies, market supply and demand, resource and environmental constraints, and technological progress, the coal chemical industry and cities will experience many economic stages of rapid growth, stability, and decline [36]. Studies have focused on the growth and decline of the petrochemical, coal chemical, and salt chemical city industries, as well as the difficulties and transformational development of these cities, which provide a good literature foundation for analyzing different types of chemical cities in China.

\subsection{Changing Location Factors of CICs' Development.} Before the 21st century, scholars focused on the impact of technology, market, raw materials, land, transportation and other factors on the layout of the chemical industry [4]. However, since the 21st century, with the acceleration of globalization, scholars have paid more attention to the new layout laws and influencing factors of the chemical industry [23]. Singapore has developed a globally competitive petrochemical industry through powerful intervention in just a few decades, which shows that government intervention is also very important [37]. Public policies and regulations, urban infrastructure, and knowledge creation and utilization are important factors for the transformation of oil industry cities [6]. Particularly, in some metropolitan areas, highspeed rail networks and industrial land efficiency are also important driving factors [38, 39]. Moreover, the development of the coal chemical industry largely depends on the price ratio of crude oil to coal [36]. A study found that high coal-consuming industries are shifting to areas with scarce coal resources, indicating that in addition to coal abundance, capital stock, human resources, and market potential also affect the industry location [19]. Studies on the layout of the chemical industry have emphasized the differences in the layouts of different industries, the factors, and mechanisms affecting the layout of the chemical industry, and especially the role of environmental regulations [40-44].

After a literature review, we found that many scholars have focused on chemical cities relying on the development of the chemical industry as a special industry and city type. Existing literature has interpreted the characteristics of agglomeration and transfer of the chemical industry, and found that in addition to raw materials, such as petroleum and coal, government intervention has had a great impact on the layout of the chemical industry and the development of the chemical industry in the city. In addition, research also shows that in the process of accelerating globalization, the division of labor between cities and even the cooperation of subindustry and industrial chains within cities have become more obvious. Existing literature also found that many traditional chemical cities are gradually getting rid of dependence on the chemical industry and attempting to transform. However, chemical cities with coal and oil as their resources are increasingly facing the "resource curse" and gradually declining. While existing studies have provided a good literature basis for this paper, they have not investigated and analyzed the rise and fall of chemical cities and industry differences at the urban scale, which are precisely the focus of this paper.

\section{Research Methods}

We established the research framework and process for this study (Figure 1). First, the enterprise spatial database was established based on the location information of enterprises, and information on the enterprises' numbers and output values was obtained for the cities. The industry agglomeration was then identified through the geographic concentration method. Furthermore, we developed an identification method of CICs and then examined the distribution, scale, and sectoral types of chemical cities. Finally, a regression model was used to explore the possible factors influencing the spatial evolutions of the layout of chemical industries and the location of CICs.

\subsection{Establishing an Enterprise Database and Sectoral Division} of Chemical Industries. This study used enterprise point data comprising the enterprises' addresses and names in the industrial enterprise database, spatially processed enterprises based on an address traceability software and ArcGIS software, and established a national chemical enterprise spatial database. The sample sizes of enterprises in 2003 and 2013 were 30,252 and 51,602, respectively. Based on the China Chemical Industry Yearbook and the National Economic Industry Classification (GB/T 4754-2011) [45], the chemical industry is defined with sector codes starting with 25 and 26 in the manufacturing industry directory. These include oil refining (sector code 251); coking (252); chemical raw materials manufacturing (261); fertilizer manufacturing (262); pesticide manufacturing (263); paints, inks, pigments, and similar products manufacturing (264); synthetic 


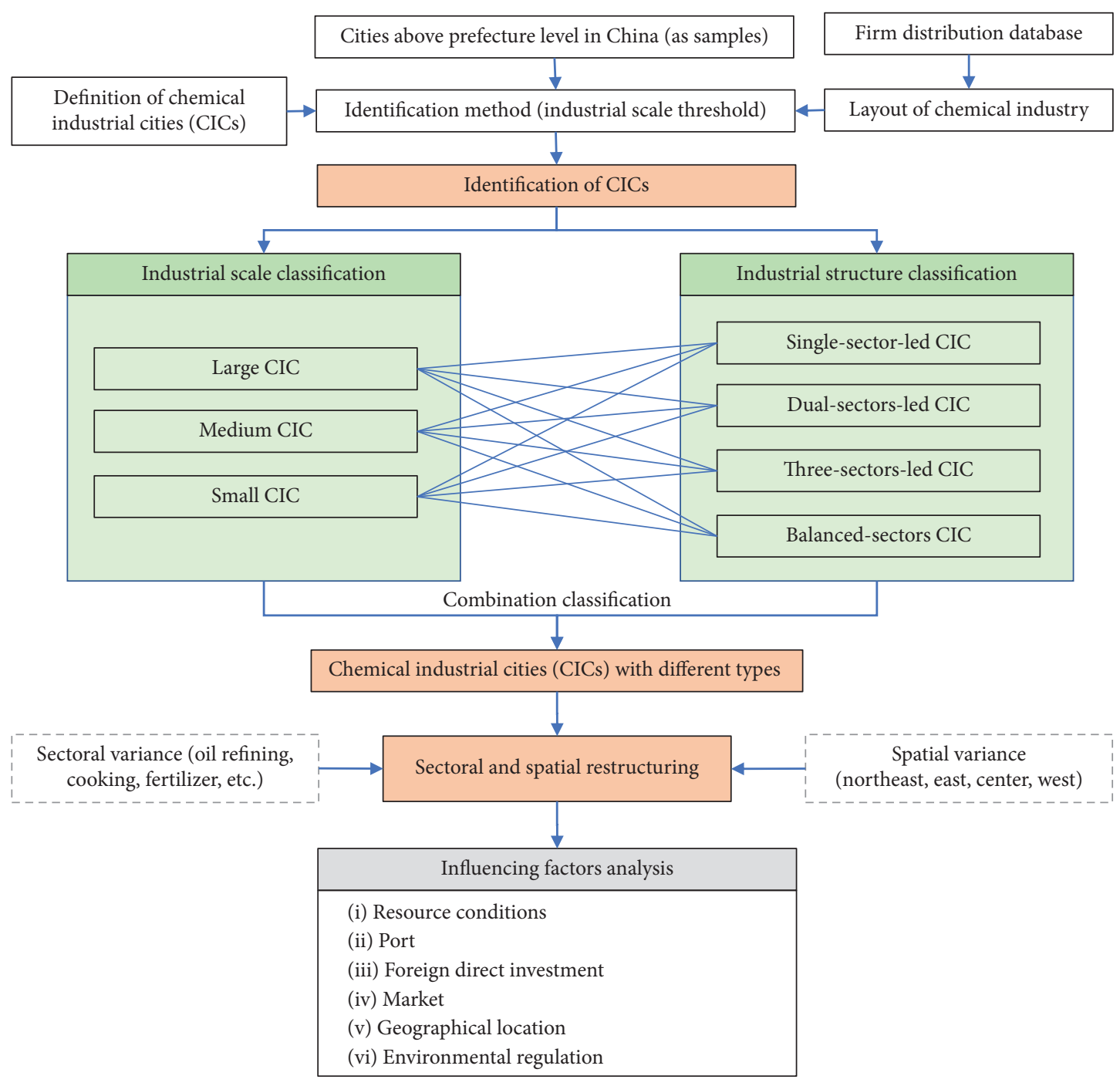

Figure 1: Research framework.

materials manufacturing (265); special chemical product manufacturing (266); explosives, pyrotechnics, and fireworks products manufacturing (267); and daily chemical products manufacturing (268).

\subsection{Measuring the Geographic Concentration of Chemical} Industries. To measure the spatial agglomeration and diffusion characteristics of the chemical industry, the absolute geographic concentration index (MHHI) was used to represent the geographic concentration [46]:

$$
\begin{gathered}
c_{i}^{k}=\frac{w_{i, k}}{\sum_{i=1}^{n} w_{i, k}}, \\
\mathrm{MHHI}^{k}=\sqrt{\frac{\sum_{i=1}^{n}\left(c_{i}^{k}\right)^{2}}{n},}
\end{gathered}
$$

where $n$ is the number of cities in the region, $W_{i k}$ is the $k$ attribute value (industry output value) in city $i, c_{i}^{k}$ reflects the share of the $k$ attribute value in city $i$ in the regional $k$ attribute, and $\mathrm{MHHI}_{k}$ is the absolute geographic concentration index of the regional $k$ attribute value. The larger the index, the more concentrated the elements are.

3.3. Identifying and Classifying CICs. The prefecture-level city administrations and municipality are used as the basic analytical unit. There are 344 city administrative units in the 31 provinces in mainland China. Based on the division of Chinese economic regions in the National Bureau of Statistics of China [47], China is divided into four regions with respect to economic geographic differences: the eastern, central, western, and northeastern regions. The eastern region is the most developed, the central and western regions are underdeveloped, and the northeastern region has old industrial bases where economic recession and urban shrinkage have emerged in recent years [34].

The classification of chemical cities is based on the existing research identifying industrial base cities [48]. An analysis of the distribution of chemical industry shares in Chinese cities found that the cumulative distribution curve of industrial shares showed a power-law distribution 
characteristic; that is, $25 \%$ of cities distributed $75 \%$ of the output value in 2013. Therefore, this demarcation point is selected as the threshold control condition, that is, the ratio of the output value is greater than $0.3 \%$ for a CIC. With expert consultation and according to the share and number of chemical industries in different cities, CICs are divided into three types based on their scale:

(i) Large CIC: city where the number of chemical enterprises is greater than 400 or the proportion of the output value is greater than $2 \%$

(ii) Medium CIC: city where the number of chemical enterprises is greater than 200 or the proportion of output value is greater than $1 \%$

(iii) Small CIC: city where the number of chemical enterprises is greater than 100 or the proportion of output value is greater than $0.3 \%$

Relevant literature on industrial specialization and a survey on the selection of leading industries in the chemical industry show that subindustries with a share of more than half of the output value can be selected as leading industries $[15,49,50]$. Thus, based on the structural characteristics of the chemical industry as well as expert consultation in Chinese cities, $60 \%$ was selected as the threshold for singleindustry identification, and thresholds for other industry structure types were proposed. Accordingly, CICs are divided into four types:

(i) Single-sector-led CIC: city where the output value of the first-class sector accounts for $60 \%$ of the total industrial output value

(ii) Dual-sectors-led CIC: city where the sum of the output value of the two types of sectors is more than $70 \%$ and the proportion of each sector is more than $15 \%$

(iii) Three-sectors-led CIC: city where the sum of the output value of the three types of sectors is more than $80 \%$ and the proportion of each sector is more than $15 \%$

(iv) Balanced-sectors-led CIC: city where the output of the four types of sectors accounts for more than $10 \%$, and the proportion of the four types of industries is relatively balanced

The chemical cities are classified into 12 types through combining of the three scale types and four industry types, and the spatial evolution of China's chemical industry and changes in city types are analyzed through changes in the sectoral and geographic locations of different types of cities.

3.4. Analyzing the Influencing Factors of CIC Development. A large number of theoretical and empirical studies have shown that the choice of urban industrial location is mainly affected by three factors: regional attributes, enterprise attributes, and government intervention [51]. In the classical and neoclassical economic models, the best locations for manufacturing companies are areas with the least production costs and the most profit $[52,53]$. Natural advantages and resource endowments often explain the location of many industries and their concentration in specific geographic spaces [54]. Accessibility of transportation and infrastructure has an important impact on urban development and corporate location selection [55]. Because of the convenience of water transportation and abundant water sources, many companies tend to lay out along the river. Under the influence of new institutional economics, increasing attention has been focused on the role of government intervention in industrial development, including environmental regulations [56]. However, the high concentration of industry, especially in the pollution sector, will increase social and environmental costs, leading to an increase in negative externalities [57], which will also affect industrial transfer. Furthermore, based on new economic geography and institutional economics, many factors, such as agglomeration economy, foreign investment, technology investment, and sales market, will affect the industrial transfer [58].

Considering the industrial location theory and referring to existing research results [32, 37, 38, 40, 41, 59-64], seven influencing factors-resource conditions, port conditions, geographic location, foreign investment, investment in science and technology, market demand, and environmental regulations-based on the representativeness of the indicators and data availability were included in the regression analysis (Table 1). The chemical industry is a distinct resource-dependent industry that also depends on port transportation $[13,20]$. It follows the general law of CIC distribution around coastal areas and large rivers [13]. Therefore, geographical location is selected as the control variable, and the geographical advantages of cities along the coast or along the Yangtze River are considered. The chemical industry is also highly dependent on the consumer market and has been restricted by environmental regulations in recent years [65]. Moreover, foreign capital brings not only capital investment to the industry but also technological upgrades, which have a positive effect on production technology and pollution prevention [42]. Therefore, the seven influencing factors we selected include regional attributes (i.e., resource conditions, port conditions, and geographic location), corporate attributes (i.e., foreign investment and market demand), and government intervention (i.e., technology investment and environmental regulations), which not only represent all aspects that affect the layout of the urban manufacturing industry but also the industry characteristics of the chemical industry.

Multiple linear regression has been used widely for statistical application as it is one of the easiest methods for numerical prediction [66]. The regression model develops linear relationships with all data points, with best approximates in a straight line, and it can be expressed as

$$
Y=C+g_{1} x_{1}+g_{2} x_{2}+\cdots+g_{n} x_{n},
$$

where $Y$ is the dependent variable (i.e., the number of chemical enterprises or the proportion of chemical industrial output value), while $x_{1}, x_{2}, \ldots, x_{n}$ are the independent variables (i.e., influencing factors in Table 1). Generally, a 
TABle 1: Definitions and descriptions of variables and their 2013 statistics.

\begin{tabular}{|c|c|c|c|c|c|}
\hline Variable & $\begin{array}{l}\text { Abbreviation } \\
\quad \text { (unit) }\end{array}$ & Description (unit) & Min & Max & SD \\
\hline Resource conditions & RES & 1 for cities with oil or coal, and 0 for cities without oil or coal & 0 & 1 & 0.23 \\
\hline Port conditions & POR & Water freight traffic volume $(10,000$ tons $)$ & 0 & 46,697 & $1,641.2$ \\
\hline Geographic location & GEO & $\begin{array}{c}1 \text { for cities along the sea or the Yangtze River, and } 0 \text { for cities far } \\
\text { from the sea or the Yangtze River }\end{array}$ & 0 & 1 & 0.27 \\
\hline Foreign investment & FDI & Proportion of foreign investment in the chemical industry (\%) & 0 & 88.64 & 11.82 \\
\hline $\begin{array}{l}\text { Investment in science and } \\
\text { technology }\end{array}$ & TEC & $\begin{array}{c}\text { Proportion of science and technology expenditure in the fiscal } \\
\text { expenditure (\%) }\end{array}$ & 0.46 & 12.31 & 2.99 \\
\hline Market demand & MAR & Population of the city $(10,000$ person $)$ & 20 & $3,358.4$ & 446.79 \\
\hline Environmental regulations & REG & Industrial sulfur dioxide removal rate (\%) & 0.10 & 99.83 & 62.00 \\
\hline
\end{tabular}

$\mathrm{SD}=$ standard deviation.

training data set is utilized to build the regression model, which is later used for prediction. The IBM SPSS statistical software is used to preform regression analysis in this study. Considering the data availability and sample size, 285 cities above the prefecture level were selected as the national regression samples.

3.5. Data Sources. The study period is 2003-2013, and the data were primarily drawn from the China Industrial Enterprises Database (2003-2013) (http://microdata.sozdata. $\mathrm{com} /$ ) and the China City Statistical Yearbook (2004-2014) [67]. From September 2016 to July 2018, field surveys and interviews were conducted in chemical parks in more than 10 cities along the middle and lower reaches of the Yangtze River, including Nanjing, Zhenjiang, Wuhan, Huanggang, Xianning, Yueyang, and Jingzhou. The purpose was to obtain first-hand interviews and survey materials to gain data support and qualitative understanding for the development of this study.

\section{Spatial Pattern and Evolution of Various CICs in China}

4.1. Spatial Pattern of Various CICs. Table 2 shows 83 and 100 CICs in 2003 and 2013, respectively. The industrial scale reflects the rise and fall of the chemical industries in the CICs, as well as the reconstruction of the overall layout of China's chemical industry. Large CICs are mainly concentrated in the eastern and northeastern coastal areas (Table 2). In 2003, large CICs were all distributed in the eastern region and in 2013, Dalian in the northeastern region (mainly in the oil refining subsector) and Changsha in the central region (mainly in the fireworks sector) were added. The distribution of large CICs can best reflect the layout strategy of the Chinese central government-that is, the focus on building seven chemical industrial bases in Dalian, Tangshan, Lianyungang, Shanghai, Ningbo, Huizhou, and Zhangzhou. Among these, Dalian, Shanghai, and Ningbo became large CICs; Lianyungang and Huizhou were medium CICs; Tangshan was a small CIC; and Zhangzhou was not developed. Moreover, China's large CICs are inclined toward the north, mainly concentrated in the coastal areas from Ningbo to Dalian (Figures 2 and 3). With the proportion of small CICs falling from $69 \%$ to $63 \%$, and the proportion of medium CICs increasing from $20 \%$ to $25 \%$ (the number increased from 16 to 25), some small CICs have a higher growth trend and development potential.

In terms of the sectoral structure, the number of balanced-sector CICs is the highest, followed by singlesector-led CICs. This reflects the aggregation of more than three sectors, thus forming an industrial chain. Singlesector-led CICs are mostly distributed in inland areas (central and western; Table 2 and Figure 4). Oil refining is the most important single-sector form, mainly distributed in oil-rich cities (e.g., Daqing, Karamay, and Yanan) and cities with oil ports or pipelines (e.g., Dalian and Qingdao; Figure 4). By 2013, Jinzhong and Linfen had withdrawn from the list of chemical cities, and Dalian, Dongying, Jiujiang, and Tangshan had transformed into the dualsectors-led model. The patterns of dual-sectors-led and three-sectors-led CICs have undergone major changes, shifting from coastal distribution to inland distribution (Table 2). Furthermore, the industrial chain models of "refining industry-chemical raw materials industry," "chemical raw materials industry-specialty chemical industries," and "chemical raw materials industry-synthetic materials industry" are relatively common development models within the dual-sectors-led and three-sectors-led CICs, mainly appearing in Jiangsu Province and Shandong Province, and Tianjin, Dalian, Jiujiang, and other large oil-refining cities and their surrounding areas. Balanced-sectors CICs are the most common, which indicate that the aggregation and diffusion trends of the chemical sectors differ between the northern and southern regions in China.

4.2. Spatial Evolution of Various CICs. CICs accounted for more than $80 \%$ ( $81.3 \%$ in 2003 and $80.2 \%$ in 2013) of China's national chemical output value in less than $30 \%$ of the cities. This reflects the overall pattern of China's chemical agglomeration cities; that is, the distribution is uneven, but relatively concentrated. From 2003 to 2013, the absolute number of chemical cities increased by 18 , reflecting the decentralized characteristics of China's chemical industry. Through the calculation of the geographic concentration index, it was found that the MHHI index of the chemical industry output value for 2003 to 2013 changed from 0.0074 to 0.0062 , which also 
TABle 2: CICs of China, 2003 and 2013.

\begin{tabular}{|c|c|c|c|c|}
\hline Year & $\begin{array}{c}\text { Sectoral } \\
\text { structure }\end{array}$ & Large & Medium & Small \\
\hline 2003 & $\begin{array}{l}\text { Single- } \\
\text { sector led }\end{array}$ & Guangzhou & $\begin{array}{c}\text { Daqing, Maoming, Jilin, Dalian, and } \\
\text { Yueyang }\end{array}$ & $\begin{array}{l}\text { Fushun, Lanzhou, Liaoyang, Luoyang, } \\
\text { Karamay, Zhuhai, Kunming, Jinzhou, } \\
\text { Yichang, Linfen, Anqing, Urumqi, Tangshan, } \\
\text { Jiujiang, Jinzhong, and Dongying }\end{array}$ \\
\hline 2003 & $\begin{array}{l}\text { Dual- } \\
\text { sectors led }\end{array}$ & - & Shaoxing and Jiangmen & $\begin{array}{l}\text { Xiamen, Wenzhou, Panjin, Huludao, } \\
\text { Taizhou, Taiyuan, Quzhou, Binzhou, Deyang, } \\
\text { Hengshui, Jingzhou, Jingmen, Guiyang, } \\
\text { Zhuzhou, and Lianyungang }\end{array}$ \\
\hline 2003 & $\begin{array}{c}\text { Three- } \\
\text { sectors led }\end{array}$ & - & - & Huai'an and Quanzhou \\
\hline 2003 & $\begin{array}{l}\text { Balanced } \\
\text { sectors }\end{array}$ & $\begin{array}{l}\text { Shanghai, Nanjing, Tianjin, } \\
\text { Beijing, Zibo, Wuxi, } \\
\text { Hangzhou, and Suzhou }\end{array}$ & $\begin{array}{c}\text { Shijiazhuang, Changzhou, Yantai, Jinan, } \\
\text { Foshan, Chongqing, Zhenjiang, and } \\
\text { Changsha }\end{array}$ & $\begin{array}{l}\text { Qingdao, Nantong, Weifang, Taizhou, } \\
\text { Shenzhen, Cangzhou, Zhongshan, Wuhan, } \\
\text { Jiaxing, Yangzhou, Taian, Yancheng, } \\
\text { Chengdu, Weihai, Dongguan, Dezhou, } \\
\text { Shenyang, Yuncheng, Jinhua, Xuzhou, Yibin, } \\
\text { Puyang, and the Administrative units of } \\
\text { Hubei Province }\end{array}$ \\
\hline 2013 & $\begin{array}{l}\text { Single } \\
\text { sector led }\end{array}$ & - & $\begin{array}{l}\text { Qingdao, Panjin, Huizhou, Maoming, } \\
\text { Daqing, Cangzhou, Beijing, Zhuzhou, } \\
\text { and Yichang }\end{array}$ & $\begin{array}{l}\text { Karamay, Jilin, Lanzhou, Yan'an, Quanzhou, } \\
\text { Luoyang, Fushun, Wuhan, Jinzhou, } \\
\text { Administrative units of Hainan Province, } \\
\text { Qinzhou, Anqing, Yinchuan, Liaoyang, } \\
\text { Urumqi, Xianyang, Yulin, Zhanjiang, } \\
\text { Luliang, Xi'an, Hengyang, and Quzhou }\end{array}$ \\
\hline 2013 & $\begin{array}{c}\text { Dual } \\
\text { sectors led }\end{array}$ & $\begin{array}{l}\text { Dongying, Ningbo, } \\
\text { Nanjing, and Dalian }\end{array}$ & Yancheng & $\begin{array}{l}\text { Jingdezhen, Xingtai, Pingxiang, Chenzhou, } \\
\text { Huhhaote, Jingdezhen, Huhhaote, Tangshan, } \\
\text { Jiujiang, Yantai, Jingdezhen, and Xingtai }\end{array}$ \\
\hline 2013 & $\begin{array}{c}\text { Three } \\
\text { sectors led }\end{array}$ & Zibo, Tianjin, and Nantong & Zhenjiang and Lianyungang & Zaozhuang, Deyang, and Nanyang \\
\hline 2013 & $\begin{array}{l}\text { Balanced } \\
\text { sectors }\end{array}$ & $\begin{array}{l}\text { Shanghai, Guangzhou, } \\
\text { Weifang, Suzhou, and } \\
\text { Changsha }\end{array}$ & $\begin{array}{c}\text { Wuxi, Changzhou, Hangzhou, Yueyang, } \\
\text { Shijiazhuang, Taizhou, Dezhou, Foshan, } \\
\text { Linyi, Chongqing, Shenyang, and } \\
\text { Xuzhou }\end{array}$ & $\begin{array}{l}\text { Binzhou, Yangzhou, Shaoxing, Jiaxing, Taian, } \\
\text { Jinan, Liaocheng, Xinxiang, efei, Huaian, } \\
\text { Zhengzhou, Puyang, Chengdu, Xiangyang, } \\
\text { Dongguan, Yingkou, Jining, Shenzhen, } \\
\text { Jiangmen, Sanming, Zhongshan, Suqian, } \\
\text { Yichun, Kaifeng, Huzhou, Ji'an, and Jinhua }\end{array}$ \\
\hline
\end{tabular}

confirmed the scattered trend of the chemical industry layout. This is consistent with related research on the distribution and dispersion laws of manufacturing or pollution-intensive industries $[40,41,59,68]$.

Compared with 2003, 35 new CICs appeared in 2013, and 15 previous CICs exited (Figure 5). In the border areas of the provinces located in the middle and lower reaches of the Yellow River, many new chemical cities (Figure 5(a)) have appeared. It is strongly indicated that these cities have undertaken a large number of industrial transfers. For example, the number of chemical companies in Heze City increased from 26 in 2003 to 243 in 2013 (Figure 5(b)). This indicates that the border areas are more susceptible to agglomeration of the chemical industry and the so-called "border effect" or "neighborhood effect" [12, 69]. Studies have shown that polluting industries tend to be located at the borders [70], and this study verifies these findings from the perspective of the chemical industry. The exiting cities are mainly located in central Shaanxi Province; for example, the number of enterprises in Linfen City reduced from 74 to 45 (Figure 5(c)). This also validates the research finding that Shaanxi's coal industry will face a difficult period of industrial development
[36]. Studies have also shown that cities in Shaanxi are in the maturity and recession stage of the coal industry [20], with significant impact from the coal chemical industry.

This study found that the main distribution areas of small, single-sector-led CICs changed from the northeast and central regions to the western region, specifically the northwestern region as it is rich in petroleum and coal resources. This type of city has an obvious location, directivity, and high dependence on resources. These cities also face excessive resource dependence ("resource curse") $[19,36]$. Moreover, small CICs with balanced sectors are mainly distributed in the North China Plain (border of Shandong Province and Henan Province).

Most small CICs are dominated by single sectors, while large and medium CICs have more balanced sectors (nearly half of them). Beijing, Shanghai, and the eastern/coastal economically developed cities are balanced-sector CICs. Among them, Beijing has changed from being a balancedsector to being a single-sector-led CIC as well as from a large to a medium CIC. Thus, it can be stated that the development idea of the chemical industry in large coastal cities is "large-scale and balanced-sectors led." By relying on the 


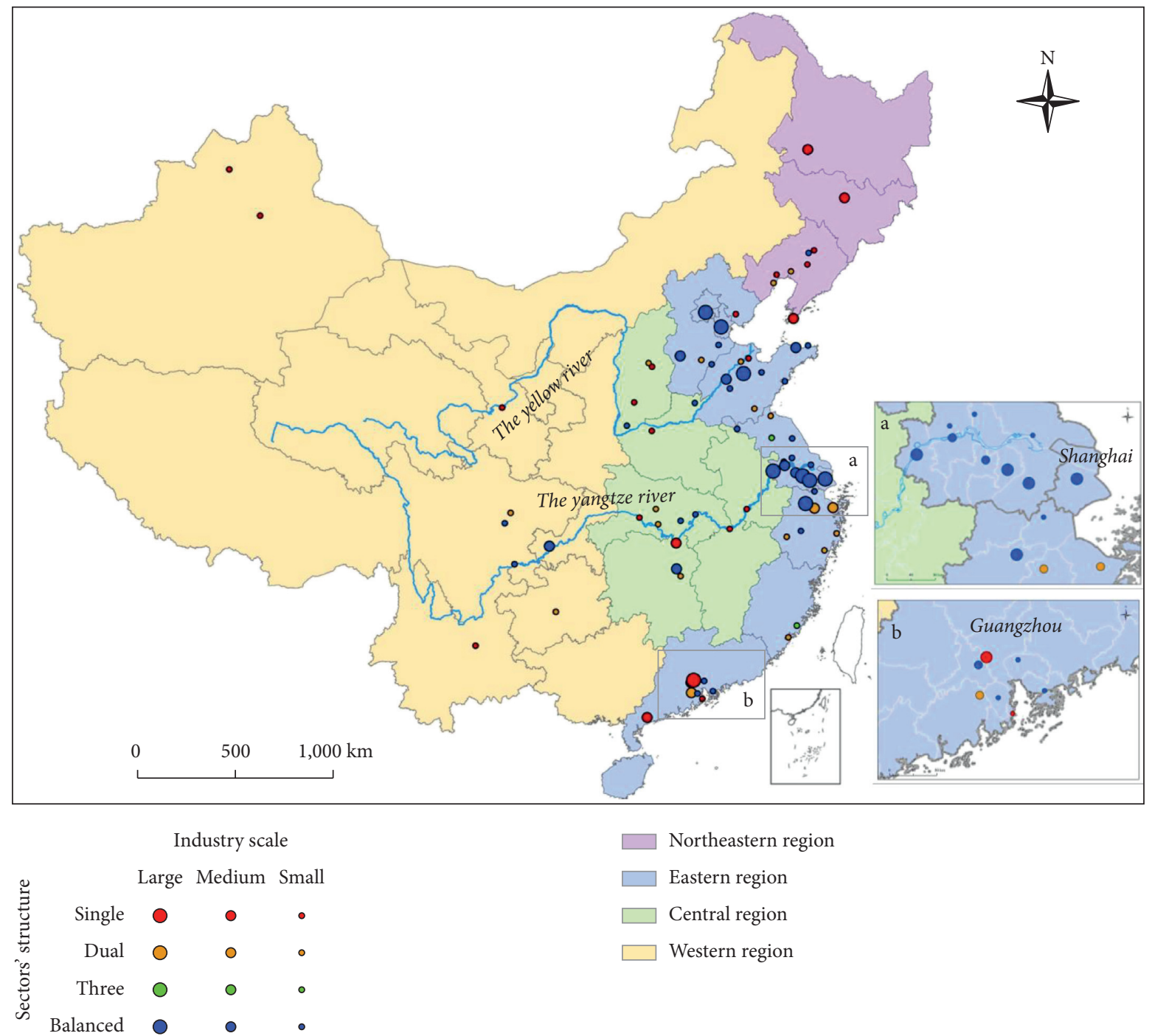

FIgURE 2: Spatial and type distribution of CICs in China, 2003.

internal sectors' division of labor and cooperation, these cities have developed a complete industrial chain and ensured strong industrial growth. In contrast, the industrial chain in the central and western regions is incomplete, as more emphasis is placed on industrial division and cooperation between small cities.

The relocation of Beijing Coking Plant to Tangshan City is a typical case (Beijing-Tangshan Case) that illustrates the comprehensive impact of the chemical sector, scale, and relocation on industrial change and city development. The Beijing Coking Plant was founded in 1958, and it was once the largest coking plant in China (Figure 6(b)). The plant was shut down in 2006-it was moved to the seaside in the neighboring Tangshan City of Hebei Province and was reorganized into the Tangshan Jiahua Coal Chemical Co., Ltd (Figures 6(a) and 6(c)). The relocation of this factory completely withdrew the coking industry from Beijing. This withdrawal and relocation of a heavily polluting industry represented by the Beijing Coking Plant also changed the industrial scale and structure of Beijing's chemical industry, where the former changed from large to medium and the latter changed from balanced sectors to single-sector led (dominated by oil refining; Figure 6(d)). Tangshan benefited from the industrial transfer of the Beijing Coking Plant and other related enterprises, and its industry structure underwent major changes, that is, from being single-sector led in 2003 (chemical raw materials accounted for 65.3\%) to dual-sectors led in 2013 (chemical raw materials accounted for $37.8 \%$ and the coking industry accounted for 56.1\%; Figure 6(e)). Among the output value of Tangshan's chemical industry, the company mentioned in the case accounted for $7.4 \%$ of the output value in 2013. This case sufficiently illustrates the profound impact of the relocation process of chemical companies on the development and structure of the 


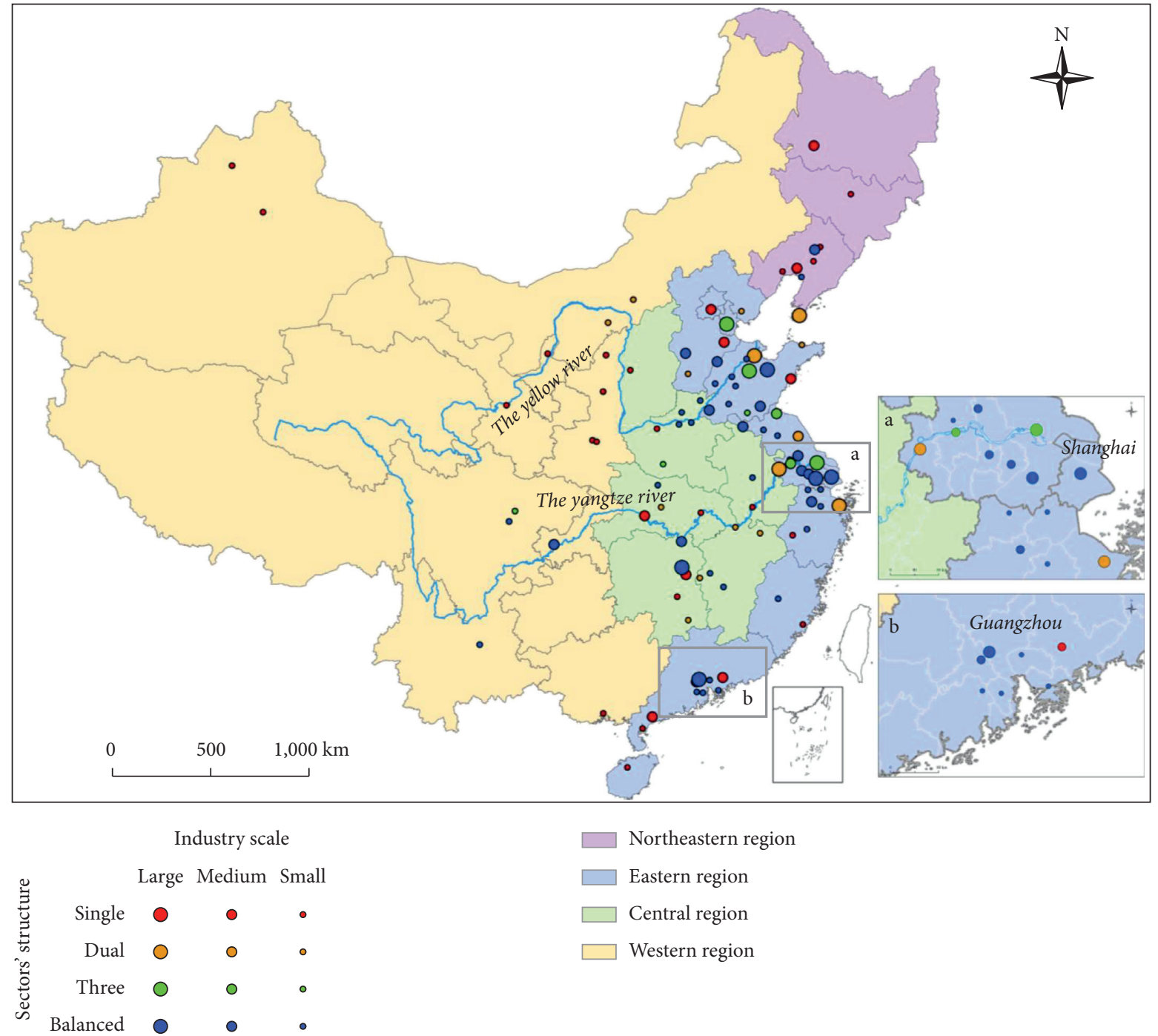

Figure 3: Spatial and type distribution of CICs in China, 2013.

chemical industry in areas from which they moved out and then moved to, as well as in the surrounding areas.

\section{Influencing Factors of the CICs' Spatial Restructuring}

The regression analysis shows that, except for the central region, each model is significant at the $99 \%$ confidence level. Tables 3 and 4 show that the overall regression in 2003 was significantly better than that in 2013 ( $R^{2}$ in 2003 was generally greater than 0.6 ), which explains the contribution, changes, and regional differences of the influencing factors. In 2003, the market, technology, and port factors had a strong and significant positive impact on the number and output value of enterprises $(p<0.01)$. By 2013, in addition to the above three factors, the positive impact of geographic factors was added. Moreover, resource conditions had a positive and significant effect on the output value of the two cross-sectional years, and foreign investment had a significant positive effect on the number of enterprises in 2013.
Except in the central region, the market factor (MAK) was not significant, and all other regions showed significant positive effects. Due to the development of standardization and modularization of chemical products, chemical production facilities can be located close to customers or suppliers [26]. This study also shows that the chemical industry has a clear market orientation, and chemical production tends to be located in areas of high consumption and population density.

At the national level, in the two cross-sectional years, the resource factor (RES) had a positive impact on the output value. In 2003, this impact was not obvious in the regions; however, it was very obvious in 2013, except for the central region-the coefficients of the northeastern, eastern, and western regions are positive with higher significance $(p<0.01$ or $p<0.05)$. This shows that China's chemical industry has not ended its resource dependence, and oil, coal, and natural gas resources are mainly distributed in the western and northeastern regions of China. In particular, the oil cities represented by Dongying, Karamay, and Daqing and the coal cities represented by Tangshan, Fushun, 


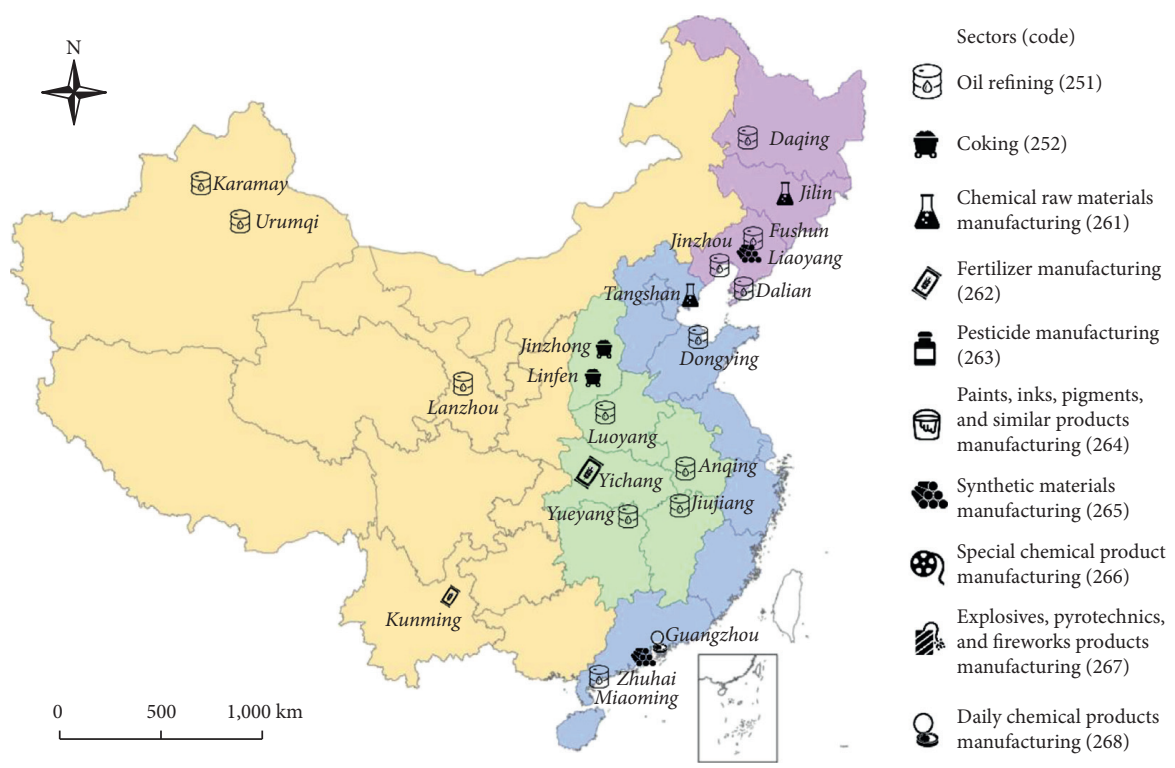

(a)

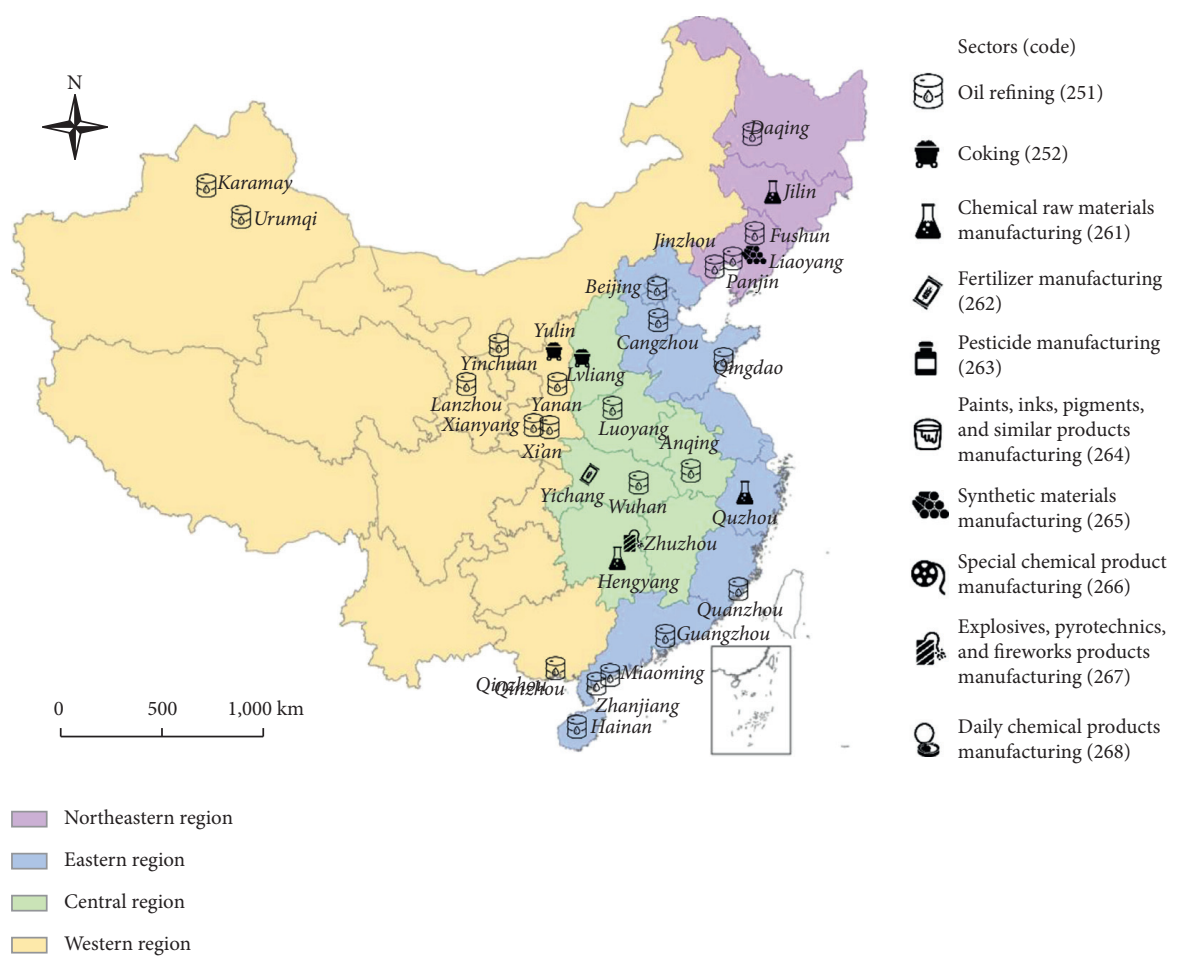

(b)

Figure 4: Spatial distribution of single-sector-led CICs in China: (a) 2003 and (b) 2013. 


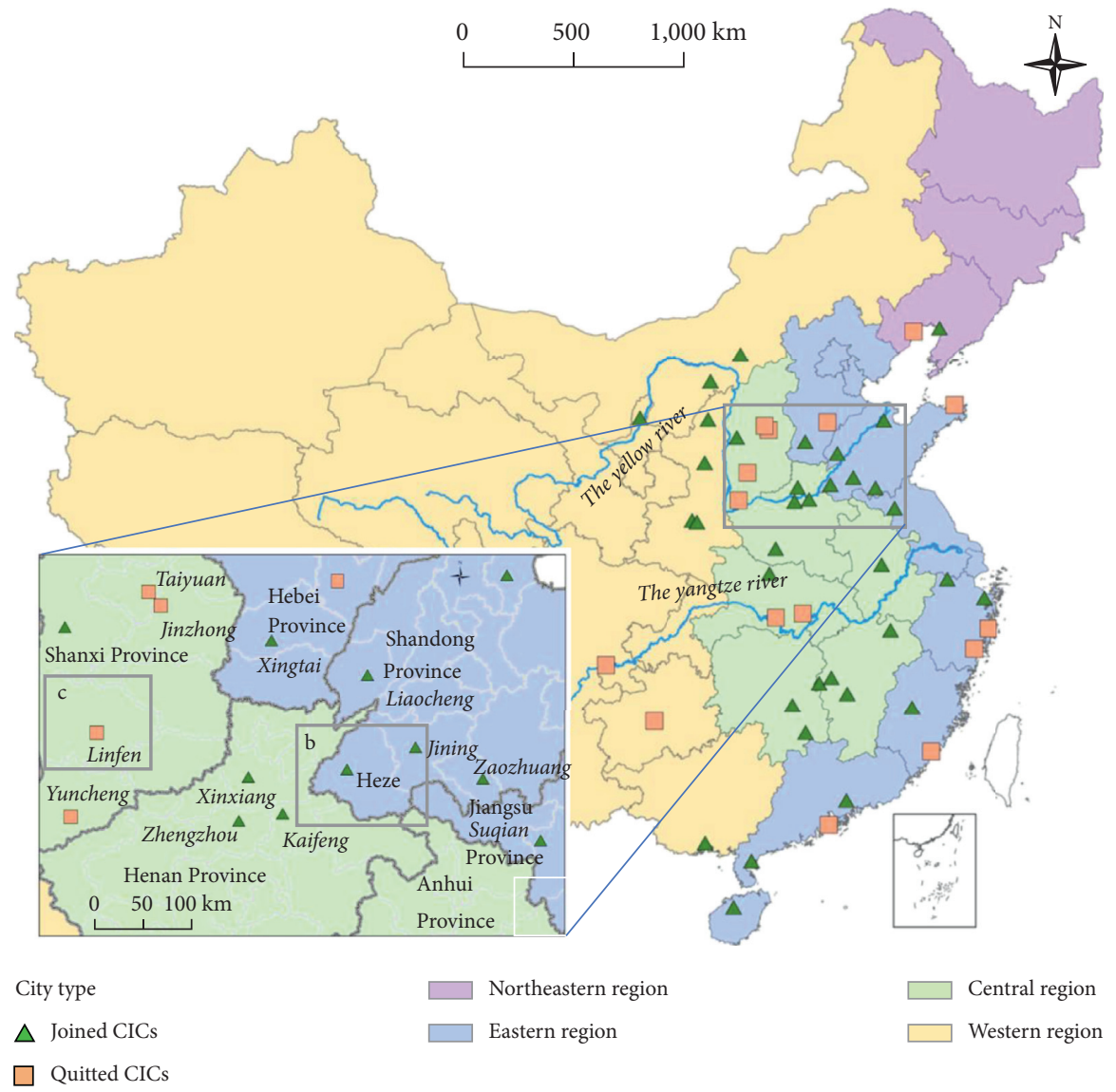

(a)
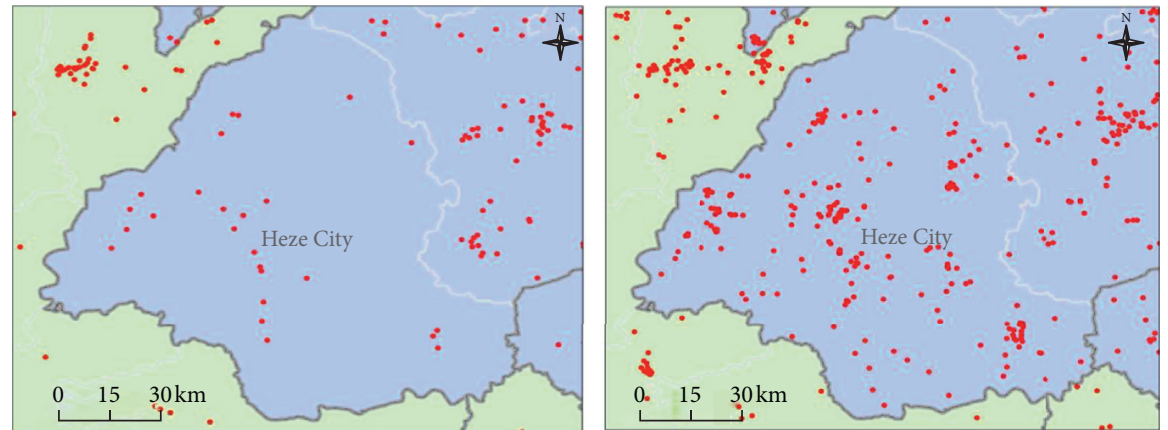

(b)
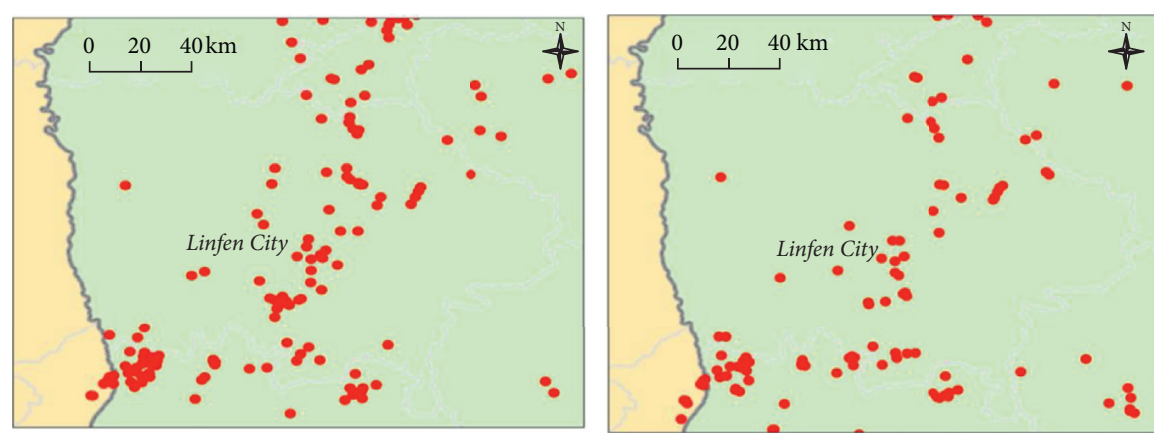

(c)

Figure 5: Changes in China's chemical industrial cities (CICs) and firms, 2003-2013. (a) Distribution of CICs that joined and quitted in China and a magnified view of middle and lower reaches of the Yellow River. (b) Firm distribution in 2003 and 2013 in Heze City, respectively. (c) Firm distribution in 2003 and 2013 in Linfen City, respectively. 


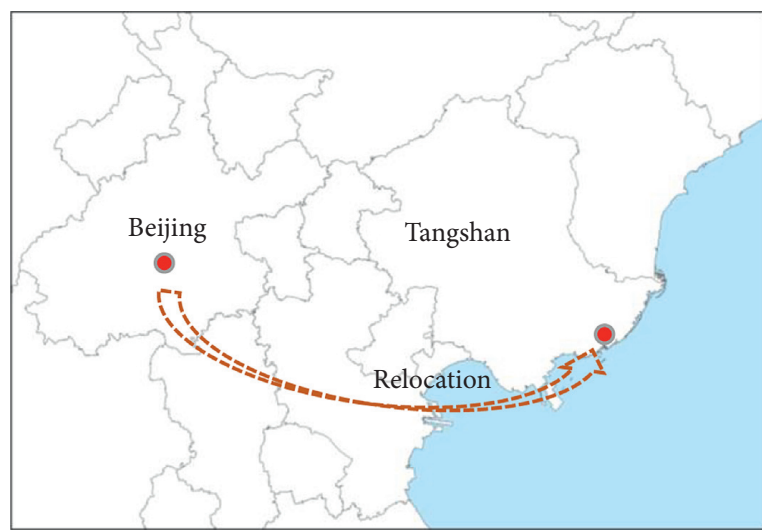

(a)

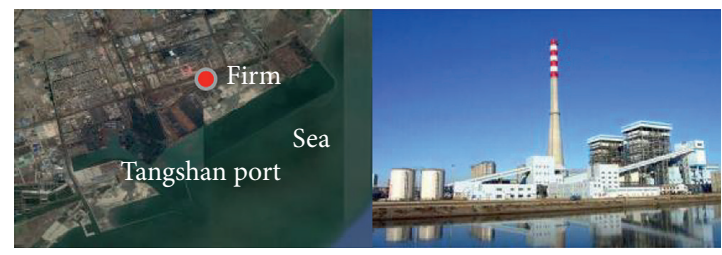

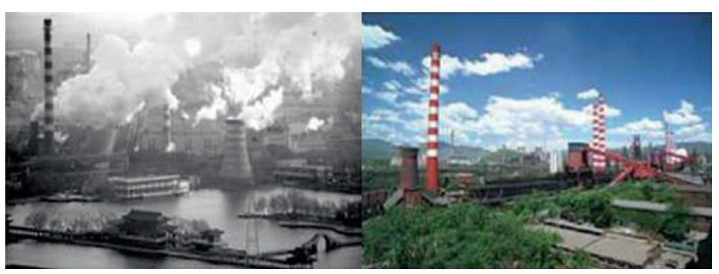

(b)

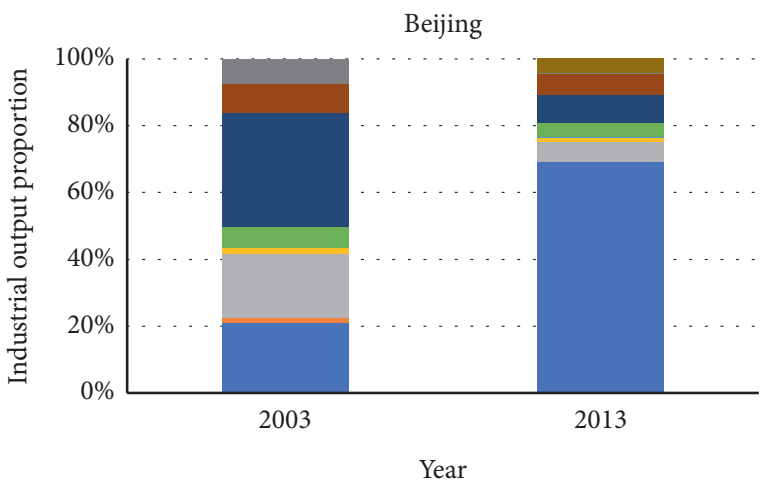

Sector code

$\begin{array}{llr}\square 251 & \square 263 & \\ \square 252 & & 266 \\ \square & 264 & 267 \\ 261 & \square 265 & 268\end{array}$

(d)

(c)

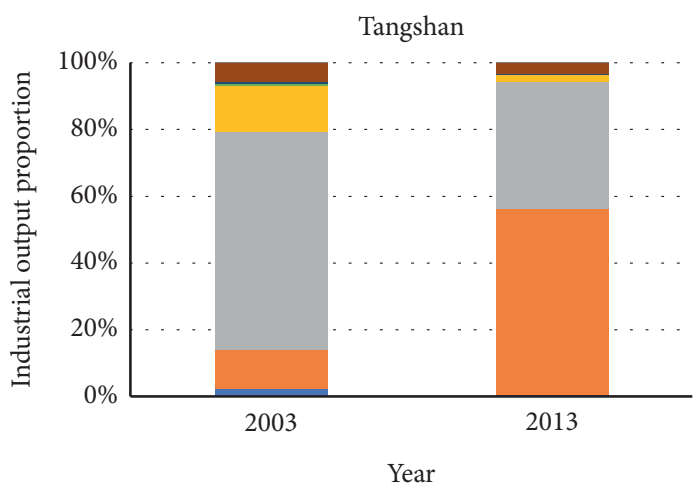

Sector code

$\begin{array}{rrr}251 & 262 & 265 \\ \square 252 & 263 & 266 \\ 261 & \square 264 & 267\end{array}$

(e)

Figure 6: Relocation of chemical companies and changes in industrial structure between Beijing and Tangshan (Beijing-Tangshan Case). (a) Location map before and after firm relocation. (b) Production and shutdown of the firm in Beijing. (c) Location and factory in Tangshan. (d) Industrial output proportion of Beijing's chemical sectors. (e) Industrial output proportion of Tangshan's chemical sectors. 


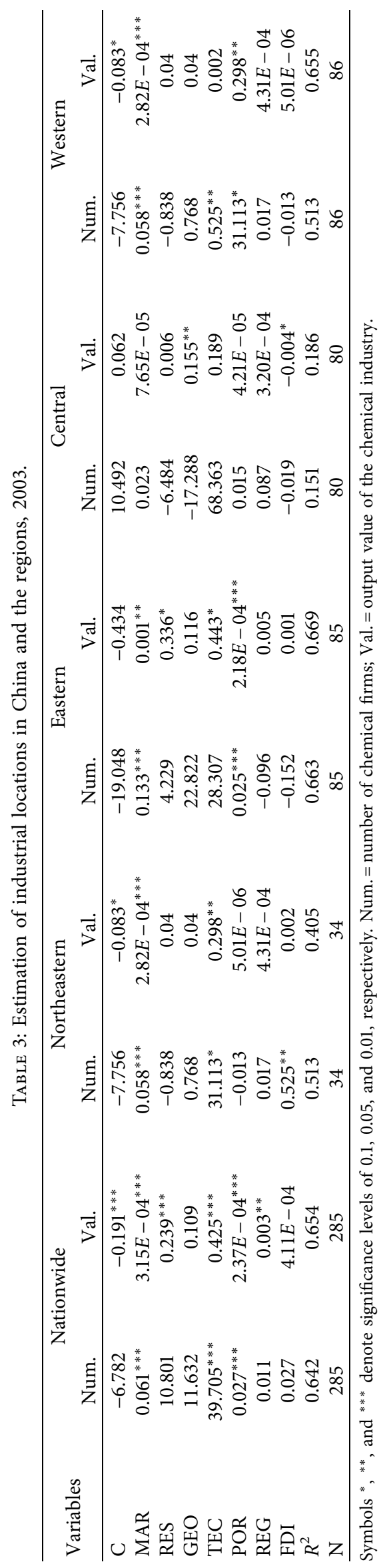




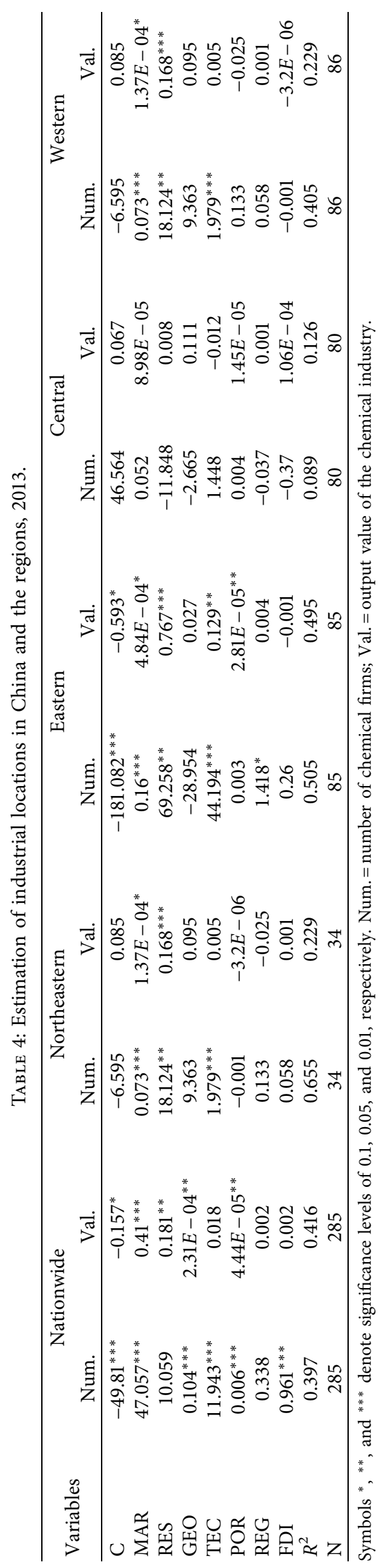


and Zaozhuang have an obvious resource orientation. Some cities, such as Yuncheng in Shaanxi Province, are shrinking due to coal depletion (Figure 5(a)). Other cities such as Ordos and Hohhot rely on the rise of coal to become emerging chemical cities (Figures 2 and 3). This shows that the rise and fall of resources largely determines the industrial destiny of chemical cities. The price ratio of crude oil to coal has also brought more complexity to the chemical layout [36].

Geographical conditions (GEO) did not have a significant impact in 2003 but had a significant impact on the national scale in 2013, especially on the number of companies $(p<0.01)$. This indicates that the economic development and coastal economic development strategies of China and the local governments along the river and coastal areas have promoted the geographical advantages of these areas. This is consistent with existing research [23]. The Beijing-Tangshan Case also reflects the process of relocating companies from inland to the seaside.

The technology factor (TEC) shows a strong and significant positive impact on the national scale, and the impact on the number of enterprises is more significant than the impact on output value. This indicates that technology is more beneficial for the development and layout of small businesses in less-developed areas. Developed regions or large enterprises controlled by the central government generally have the highest capital and technology levels, and they can end their excessive dependence on technology. Because of the increasing dependence on technology in chemical production and pollution prevention, more CICs are paying attention to technology investment. The CICs represented by Anqing, Yancheng, and Deyang were ranked at the top in the country in terms of technology investment in 2013 .

The port factor (POR) had a strong and significant impact at the national scale. In terms of regions, the eastern region had the strongest influence $(p<0.01$ in 2003, $p<0.1$ in 2013). The eastern coastal areas had a comparative advantage for the transportation of chemical raw materials and products. This confirms that the chemical industry has high dependence on port shipping traffic. For example, the enterprises in the Beijing-Tangshan Case had relocated near a port (Figure 6(c)). This factor also affected shipping in inland ports. For example, the total water transportation in Xuzhou increased from 6.2 million tons to 48.0 million tons in 2003-2013. Studies also show that industries and the economy of Chinese port cities are developing significantly faster than those of nonport cities [71]. The change in the regression coefficient reflects port conditions that have significantly decreased their output value, which may be related to the improvement in the national comprehensive transportation network and construction of oil and gas pipelines.

The environmental regulatory factor (REG) is not in line with the expectations and did not have a significant negative impact. It had a positive impact on the output value at the national scale in 2003 and on the number of enterprises in the eastern region in 2013. This shows that Chinese environmental regulations do not restrain chemical companies from the perspective of exhaust emissions control.
Metropolises, such as Beijing, Shanghai, and Guangzhou, as well as other important ecologically sensitive areas continue to promote the closure and relocation of polluting enterprises through environmental regulations. Although environmental regulations have a real impact in some local areas, their effect is still uncertain and complex at the national scale in China.

Foreign direct investment (FDI) did not have a significant impact at the national level in 2003, and the coefficient of the number of enterprises in 2013 was positive $(p<0.01)$. This indicates that the influence of FDI on the layout of China's chemical industry is gradually increasing. The proportion of FDI in chemical output value increased from $19.2 \%$ to $22.5 \%$. Cities with a high proportion of foreign investors are mainly distributed along the southeast coast and the Yangtze River Delta. Among them, Xiamen is the most typical city with a foreign orientation. In $2013,89 \%$ of Xiamen's chemical companies received FDI. Moreover, the proportion of FDI in Quanzhou increased from 31\% to 75\%, prompting the proportion of chemical output value to rise from $0.4 \%$ to $0.7 \%$. In addition, Shanghai, Zhenjiang, Suzhou, Guangzhou, and Zhanjiang are all foreign-oriented cities. In the Beijing-Tangshan Case, German capital was added to the relocated coal chemical enterprise.

\section{Conclusion and Discussion}

Literature has focused on the layout of the chemical industry and its spatial relationship with the city. However, research on the rise and fall of chemical cities and industrial restructuring on a regional scale is scarce. The regional and industrial differences in the quantitative measurement of national-scale chemical cities and their temporal and spatial impacts are rarely studied. In order to fill this research gap, we studied the restructuring of China's chemical city and its impact. We focused on the rise and fall of chemical cities, while directing special attention to the differences in industries and geographic factors.

We found that China's chemical production capacity is mainly concentrated in a few cities; however, this concentration is weakening, that is, the chemical distribution is decentralized. This reflects the process of China's industrialization, that is, developed regions continue to carry out industrial replacement, and underdeveloped regions undertake basic industries represented by the chemical industry to achieve industrialization. The reduction of coal CICs, represented by Shaanxi Province (with abundant coal), and the overall prosperity of petrochemical industries, represented by Shandong Province (with abundant oil), reflect the international trend of the chemical industry's shift from the coal chemical industry to the petrochemical industry. In line with existing research, coal chemical cities have experienced a change from prosperity to decline [36]. Large CICs are mainly located in the eastern and northeastern coastal areas-specifically concentrated in the coastal areas from Ningbo to Dalian. This reflects the Chinese central government's strategy regarding the layout of the chemical industry (i.e., the strategy of developing seven major CICs); it also indicates that the strategies have 
experienced deviations or developmental lags (e.g., in Tangshan and Zhangzhou). This is also related to the location advantages of coastal port traffic and the dense environmental capacity, reflecting the general law of the coastal layout of global chemical cities.

We further found that single-sector-led CICs are dominated by the oil-refining sector, which is mainly distributed in inland areas (central and western). Small singlesector-led cities have shifted from old industrial cities in the northeast and central regions to the western region, specifically Shanxi, Shaanxi, and Xinjiang provinces, which are rich in oil and coal. The chemical development of large CICs in the eastern coastal regions still involves "large scale and balanced sectors", and the cities' internal industrial chain is complete; however, the division of labor between the cities is insufficient. In addition, the industrial division of labor between cities in the central and western regions is more distinct. Studies have found that some single-industry cities have experienced a sharp transition from prosperity to decline, while multi-industry cities are more likely to maintain their prosperity [72]. In contrast, research on manufacturing has reached the opposite conclusion, that specialization promotes the growth of the urban industry, while diversity has no effect [15]. We examined this law in terms of the chemical industry; the more diverse the chemical sectors, the larger the scale of the city's chemical industry and the more prosperous the development.

We found that markets, resources, geography, ports, and foreign investment all have a positive effect on the distribution of the chemical industry and changes in the CICs, especially on the increase in geographic factors and foreign investment. In the eastern market, the port factor has a significant impact. This is due to the rapid development of China's coastal and inland port transportation, which has played a huge role in the transportation of raw materials and products in chemical cities [31]. This has also prompted the transformation of the chemical city from the layout of raw materials to the advantageous layout of water transportation. The central region as a whole is not significant, while the resource factor in the western region is significant. Furthermore, the market in Northeast China is driven significantly by resources and technological factors. With the escalation of unilateralism and trade protectionism in the world, geopolitical risks have intensified further, and market fluctuations in petroleum and chemical products have exacerbated the development and layout of the chemical industry [73]. Changes in the chemical industry may also be related to topography and landforms. Relevant research shows that since 2010, cities in the central, northern, and northeastern plains of China are sufficiently flat for urban expansion and industrial land construction, including for chemical industries $[34,74]$. Therefore, many new CICs have emerged in the North China Plain, likely due to the flat terrain.

In addition, this paper presents the following policymaking enlightenment. First, the disorderly decentralization of the chemical industry is an important cause of pollution transfer and risks. Therefore, the Chinese central government should strictly control the transfer of the chemical industry, especially the heavily polluting industries, to the fragile ecological environment. At the same time, it should delineate cities where the chemical industry will focus on layout, and formulate optimized plans for subindustry division and industrial chain cooperation [75]. Many explorations have been done in the areas along the Yangtze River [76], and the experience should be summed up in other regions. Second, the Chinese central government should actively guide the transformation and upgrading of weak chemical cities and cultivate new, high-quality chemical cities. For the old and declining chemical cities, it should provide policies and funds for transformation and development to get rid of the "resource curse.". For emerging chemical cities, it should provide technical support, improve environmental regulations, and avoid "pollution transfer." Third, it should strengthen the construction of infrastructure to support the development of the urban chemical industry, with emphasis on strengthening the construction of chemical port terminals and water transportation systems. This will facilitate the transportation of chemical raw materials and products throughout China and the world, and improve the regional and global links of chemical cities.

\section{Data Availability}

The data used to support the findings of this study are available from the corresponding author upon request.

\section{Conflicts of Interest}

The authors declare that they have no conflicts of interest.

\section{Acknowledgments}

This work was supported by the National Natural Science Foundation of China (Grant No. 41901156) and Project of the Nanjing Institute of Geography and Limnology, Chinese Academy of Sciences (Grant No. NIGLAS2019QD011).

\section{References}

[1] K. E. Lee, M. Mokhtar, C. T. Goh, H. Singh, and P. W. Chan, "Initiatives and challenges of a chemical industries council in a developing country: the case of Malaysia," Journal of Cleaner Production, vol. 86, pp. 417-423, 2015.

[2] G. Angerer, R. Nordbeck, and C. Sartorius, "Impacts on industry of Europe's emerging chemicals policy REACh," Journal of Environmental Management, vol. 86, no. 4, pp. 636-647, 2008.

[3] S. Axon and D. James, "The UN sustainable development goals: how can sustainable chemistry contribute? A view from the chemical industry," Current Opinion in Green and Sustainable Chemistry, vol. 13, pp. 140-145, 2018.

[4] N. A. Powe and K. G. Willis, "Industrial location and residential disamenity: a case study of the chemical industry in Castleford, England," Journal of Environmental Management, vol. 53, no. 1, pp. 17-29, 1998.

[5] R. P. Lee, "Alternative carbon feedstock for the chemical industry?-assessing the challenges posed by the human dimension in the carbon transition," Journal of Cleaner Production, vol. 219, pp. 786-796, 2019. 
[6] A. K. M. Tarigan, D. A. A. Samsura, S. Sagala, and R. Wimbardana, "Balikpapan: urban planning and development in anticipation of the post-oil industry era," Cities, vol. 60, pp. 246-259, 2017.

[7] L. Gan, H. Shi, Y. Hu, B. Lev, and H. Lan, "Coupling coordination degree for urbanization city-industry integration level: Sichuan case," Sustainable Cities and Society, vol. 58, 2020.

[8] O. Genc, A. Kurt, D. M. Yazan, and E. Erdis, "Circular ecoindustrial park design inspired by nature: an integrated nonlinear optimization, location, and food web analysis," Journal of Environmental Management, vol. 270, Article ID 110866, 2020.

[9] W. Lasschuit and N. Thijssen, "Supporting supply chain planning and scheduling decisions in the oil and chemical industry," Computers \& Chemical Engineering, vol. 28, no. 6-7, pp. 863-870, 2004.

[10] Q. Han, Y. Wang, L. Shen, and W. Dong, "Decision and coordination of low-carbon E-Commerce supply chain with government carbon subsidies and fairness concerns," Complexity, vol. 2020, Article ID 1974942, 19 pages, 2020.

[11] C. Hu, Y. Zhou, and C. He, "Regional industrial development in a dual-core industry space in China: the role of the missing service," Habitat International, vol. 94, Article ID 102072, 2019.

[12] Y. Wu, Y. D. Wei, and L. Han, "Firm suburbanization in the context of Urban sprawl: neighborhood effect and sectoral difference," The Professional Geographer, vol. 72, no. 4, 2020.

[13] C. M. Marques, S. Moniz, J. P. de Sousa, A. P. Barbosa-Povoa, and G. Reklaitis, "Decision-support challenges in the chemical-pharmaceutical industry: findings and future research directions," Computers \& Chemical Engineering, vol. 134, Article ID 106672, 2020.

[14] C. Chen and G. Reniers, "Chemical industry in China: the current status, safety problems, and pathways for future sustainable development," Safety Science, vol. 128, Article ID 104741, 2020.

[15] Y. Lu, J. Ni, Z. Tao, and L. Yu, "City-industry growth in China," China Economic Review, vol. 27, pp. 135-147, 2013.

[16] H. Li, J. Lu, and B. Li, "Does pollution-intensive industrial agglomeration increase residents' health expenditure?” Sustainable Cities and Society, vol. 56, 2020.

[17] S.-R. Lim, C. W. Lam, and J. M. Schoenung, "Priority screening of toxic chemicals and industry sectors in the U.S. toxics release inventory: a comparison of the life cycle impactbased and risk-based assessment tools developed by U.S. EPA," Journal of Environmental Management, vol. 92, no. 9, pp. 2235-2240, 2011.

[18] A. Dakkoune, L. Vernières-Hassimi, S. Leveneur, D. Lefebvre, and L. Estel, "Analysis of thermal runaway events in French chemical industry," Journal of Loss Prevention in the Process Industries, vol. 62, Article ID 103938, 2019.

[19] M. Song, J. Wang, and J. Zhao, "Coal endowment, resource curse, and high coal-consuming industries location: analysis based on large-scale data," Resources, Conservation and Recycling, vol. 129, pp. 333-344, 2018.

[20] F. Ruan, L. Yan, and D. Wang, "The complexity for the resource-based cities in China on creating sustainable development," Cities, vol. 97, Article ID 102571, 2020.

[21] S. Moser, M. Swain, and M. H. Alkhabbaz, "King abdullah economic city: engineering Saudi Arabia's post-oil future," Cities, vol. 45, pp. 71-80, 2015.

[22] S. Moser, G. Fauveaud, and A. Cutts, "Montréal: towards a post-industrial reinvention,” Cities, vol. 86, pp. 125-135, 2019.
[23] W. Zhang, K. Dong, and S. Tian, "Development and evolution of spatial distribution of Chinese petrochemical industry," Geographical Research, vol. 28, no. 5, pp. 1378-1388, 2009.

[24] W. Molle and E. Wever, "Oil refineries and petrochemical industries in Europe," GeoJournal, vol. 9, no. 4, pp. 421-430, 1984.

[25] L. Lin, "Innovation dynamics and spatial response of heavychemical industry: rethinking the cluster innovation," Acta Geographica Sinica, vol. 71, no. 8, pp. 1400-1415, 2016.

[26] T. Becker, S. Lier, and B. Werners, "Value of modular production concepts in future chemical industry production networks," European Journal of Operational Research, vol. 276, no. 3, pp. 957-970, 2019.

[27] W. Jici, "Discussion on the layout and site selection of China's petroleum chemical fiber industry," Economic Geography, vol. 2, no. 3, pp. 194-199, 1982.

[28] J. Brömer, M. Brandenburg, and S. Gold, "Transforming chemical supply chains toward sustainability-A practicebased view," Journal of Cleaner Production, vol. 236, Article ID 117701, 2019.

[29] J. M. Laínez and L. Puigjaner, "Prospective and perspective review in integrated supply chain modelling for the chemical process industry," Current Opinion in Chemical Engineering, vol. 1, no. 4, pp. 430-445, 2012.

[30] W. Gou, S. Huang, Q. Chen, J. Chen, and X. Li, "Structure and dynamic of global population migration network," Complexity, vol. 2020, Article ID 4359023, 17 pages, 2020.

[31] S. Guo, Y. Li, Y. Hu, F. Xue, B. Chen, and Z.-M. Chen, "Embodied energy in service industry in global cities: a study of six Asian cities," Land Use Policy, vol. 91, Article ID 104264, 2020.

[32] S. Y. He, J. Lee, T. Zhou, and D. Wu, "Shrinking cities and resource-based economy: the economic restructuring in China's mining cities," Cities, vol. 60, pp. 75-83, 2017.

[33] S. Ren, D. Liu, B. Li, Y. Wang, and X. Chen, "Does emissions trading affect labor demand? Evidence from the mining and manufacturing industries in China," Journal of Environmental Management, vol. 254, Article ID 109789, 2020.

[34] Y. Deng, W. Qi, B. Fu, and K. Wang, "Geographical transformations of Urban sprawl: exploring the spatial heterogeneity across cities in China 1992-2015," Cities, vol. 105, Article ID 102415, 2019.

[35] Q. Wu, X. Zhang, Z. Shang, and Z. Li, "Political-economy based institutional industry complex and sustainable development: the case of the salt-chemical industry in Huai'an, China," Energy Policy, vol. 87, pp. 39-47, 2015.

[36] J. Li and S. Hu, "History and future of the coal and coal chemical industry in China," Resources, Conservation and Recycling, vol. 124, pp. 13-24, 2017.

[37] K. M. Vu, "Embracing globalization to promote industrialization: insights from the development of Singapore's petrochemicals industry," China Economic Review, vol. 48, pp. 170-185, 2018.

[38] C. Li, X. Gao, B. J. He, J. Wu, and K. Wu, "Coupling coordination relationships between urban-industrial land use efficiency and accessibility of highway networks: evidence from beijing-Tianjin-hebei urban agglomeration, China," Sustainability, vol. 11, no. 5, 2019.

[39] C. Li, X. Gao, J. Wu, and K. Wu, "Demand prediction and regulation zoning of urban-industrial land: evidence from Beijing-Tianjin-Hebei Urban Agglomeration, China," Environmental Monitoring and Assessment, vol. 191, no. 7, p. 412, 2019. 
[40] J. Shen, Y. D. Wei, and Z. Yang, "The impact of environmental regulations on the location of pollution-intensive industries in China," Journal of Cleaner Production, vol. 148, pp. 785-794, 2017.

[41] F. Yuan, Y. D. Wei, J. Gao, and W. Chen, "Water crisis, environmental regulations and location dynamics of pollution-intensive industries in China: a study of the Taihu Lake watershed," Journal of Cleaner Production, vol. 216, pp. 311322, 2019.

[42] Y. Jiahuey, Y. Liu, and Y. Yu, "Measuring green growth performance of China's chemical industry," Resources, Conservation and Recycling, vol. 149, pp. 160-167, 2019.

[43] J. Zhang, L. Kang, H. Li, P. Ballesteros-Pérez, M. Skitmore, and J. Zuo, "The impact of environmental regulations on urban Green innovation efficiency: the case of Xi'an," Sustainable Cities and Society, vol. 57, 2020.

[44] X. Wang, C. Zhang, and Z. Zhang, "Pollution haven or porter? The impact of environmental regulation on location choices of pollution-intensive firms in China," Journal of Environmental Management, vol. 248, Article ID 109248, 2019.

[45] NBS, "Industrial classification of National Economy," 2013, http://www.stats.gov.cn/statsinfo/auto2073/201406/ t20140606_564743.html.

[46] Q. Wang, Y. Jiang, and Z. Chen, Regional Economic Research and Practical Methods: Based on ArcGIS, GeoDa and R Application, Economic Science Press, Beijing, China, 2014.

[47] NBS, "The division of central, east, west and northeast China," 2011, http://www.stats.gov.cn/ztjc/zthd/sjtjr/dejtjkfr/tjkp/ 201106/t20110613_71947.htm.

[48] F. Jin, L. Chen, and Y. Yang, "The classification and growth pattern of industrial bases in China," Acta Geographica Sinica, vol. 73, no. 6, pp. 1049-1064, 2018.

[49] Q. He, C. Xue, and S. Zhou, "Does contracting institution affect the patterns of industrial specialization in China?" China Economic Review, vol. 54, pp. 191-203, 2019.

[50] S. B. Billings and E. B. Johnson, "A non-parametric test for industrial specialization," Journal of Urban Economics, vol. 71, no. 3, pp. 312-331, 2012.

[51] D. Zheng and M. Shi, "Industrial land policy, firm heterogeneity and firm location choice: evidence from China," Land Use Policy, vol. 76, pp. 58-67, 2018.

[52] R. Hayter, The Dynamics of Industrial Location: The Firm the Factory and the Production System, Wiley, Hoboken, NJ, USA, 1997.

[53] A. Weber, "Theory of the location of industries," Nature, vol. 15 , no. 1 , p. $1,1960$.

[54] M. A. López-Navarro, V. Tortosa-Edo, and V. Castán-Broto, "Firm-local community relationships in polluting industrial agglomerations: how firms' commitment determines residents' perceptions," Journal of Cleaner Production, vol. 186, pp. 22-33, 2018.

[55] C. He, Y. D. Wei, and X. Xie, "Globalization, institutional change, and industrial location: economic transition and industrial concentration in China," Regional Studies, vol. 42, no. 7, pp. 923-945, 2008.

[56] A. Bevan, S. Estrin, and K. Meyer, "Foreign investment location and institutional development in transition economies," International Business Review, vol. 13, no. 1, pp. 43-64, 2004.

[57] E. Kyriakopoulou and A. Xepapadeas, "First nature advantage and the emergence of economic clusters," Regional Science and Urban Economics, vol. 43, no. 1, pp. 101-116, 2013.

[58] J. M. Arauzo-Carod, D. Liviano-Solis, and M. ManjonAntolin, "Empirical studies IN industrial location: an assessment of their methods and results*," Journal of Regional Science, vol. 50, no. 3, pp. 685-711, 2010.

[59] J. Wu, Y. D. Wei, W. Chen, and F. Yuan, "Environmental regulations and redistribution of polluting industries in transitional China: understanding regional and industrial differences," Journal of Cleaner Production, vol. 206, pp. 142-155, 2019.

[60] K. Chapman, "Industry evolution and international dispersal: the fertiliser industry," Geoforum, vol. 31, no. 3, pp. 371-384, 2000.

[61] J. Yang, X. Luo, C. Jin, X. Xiao, and J. Xia, "Spatiotemporal patterns of vegetation phenology along the urban-rural gradient in Coastal Dalian, China," Urban Forestry \& Urban Greening, vol. 54, Article ID 126784, 2020.

[62] J. Yang, S. Jin, X. Xiao et al., "Local climate zone ventilation and urban land surface temperatures: towards a performancebased and wind-sensitive planning proposal in megacities," Sustainable Cities and Society, vol. 47, Article ID 101487, 2019.

[63] M. Chen, X. Luo, M. Hu, and X. Zhang, "Club characteristic and the proximity effect of Travel links between cities in China," Complexity, vol. 2020, Article ID 5786384, 13 pages, 2020.

[64] Z. Yang and C. Li, "Spatial and temporal characteristics of rurality in urban Suburb Town and its driving factors based on land use transformation," Complexity, vol. 2020, Article ID 2806127, 10 pages, 2020.

[65] V. Prado, R. Glaspie, R. Waymire, and L. Laurin, "Energy apportionment approach to incentivize environmental improvement investments in the chemical industry," Journal of Cleaner Production, vol. 257, Article ID 120550, 2020.

[66] D. R. Patel and M. B. Kiran, "A non-contact approach for surface roughness prediction in $\mathrm{CNC}$ turning using a linear regression model," Materials Today: Proceedings, vol. 26, pp. $350-355,2020$.

[67] China Statistics Press, China City Statistical Yearbook, China Statistics Press, Beijing, China, 2014.

[68] J. Shen, S. Wang, W. Liu, and J. Chu, "Does migration of pollution-intensive industries impact environmental efficiency? Evidence supporting "pollution haven hypothesis"” Journal of Environmental Management, vol. 242, pp. 142-152, 2019.

[69] F. Scorza, A. Pilogallo, L. Saganeiti, B. Murgante, and P. Pontrandolfi, "Comparing the territorial performances of renewable energy sources' plants with an integrated ecosystem services loss assessment: a case study from the Basilicata region (Italy)," Sustainable Cities and Society, vol. 56, 2020.

[70] X. Yang and C. He, "Do polluting plants locate in the borders of jurisdictions? Evidence from China," Habitat International, vol. 50, pp. 140-148, 2015.

[71] J. Guo, Y. Qin, X. Du, and Z. Han, "Dynamic measurements and mechanisms of coastal port-city relationships based on the DCI model: empirical evidence from China," Cities, vol. 96, Article ID 102440, 2020.

[72] J. Wang, Z. Yang, and X. Qian, "Driving factors of urban shrinkage: examining the role of local industrial diversity," Cities, vol. 99, Article ID 102646, 2020.

[73] C. Zeng and Q. Hu, "2018 petroleum \& chemical industry development report," Chinese Journal of Chemical Engineering, vol. 27, no. 10, pp. 2606-2614, 2019.

[74] G. Yin, Z. Lin, X. Jiang, M. Qiu, and J. Sun, "How do the industrial land use intensity and dominant industries guide the urban land use? Evidences from 19 industrial land categories in ten cities of China," Sustainable Cities and Society, vol. 53, Article ID 101978, 2020. 
[75] R. K. Rajeev, R. K. Pati, and S. S. Padhi, "Sustainable supply chain management in the chemical industry: evolution, opportunities, and challenges," Resources, Conservation and Recycling, vol. 149, pp. 275-291, 2019.

[76] Y. Liu, X. Zhang, X. Pan, X. Ma, and M. Tang, "The spatial integration and coordinated industrial development of urban agglomerations in the Yangtze River Economic Belt, China," Cities, vol. 104, Article ID 102801, 2020. 